\title{
A Framework for Investigating the ERP System Quality from Users Point of View in Indian Industries
}

\author{
Suraj Kumar Mukti, Priyanka Tripathi, and A. M. Rawani
}

\begin{abstract}
It has been close to 15 years since the word ERP has been used in the Indian market. The Indian ERP market is currently estimated to be worth Rs 40, 0000 million and is expected to grow at a CAGR of 25 percent in the next 3-4 years. Avery high failures rate of ERP, 93\% (approx) makes it a very critical issue which needs an immediate attention. Less work has been done to evaluate the quality of ERP in its operative phase in Indian Industries. The authors have proposed a systematic design of quality evaluation method, in order to investigate the quality of ERP in Indian Industries. Four quality factors namely usability, functionality, reliability and efficiency have been considered to evaluate the ERP to measure the quality from the user's point of view. By combining the outcome of each factor, we find out the Global Quality Preference of the ERP in that industry. ISO/IEC 9126 has been used as a base model for this work.
\end{abstract}

Index Terms - Quality, evaluation, usability, functionality, reliability, efficiency, ERP.

\section{INTRODUCTION}

Even though software industry is more than three decades old but it still eludes suitable quality models that can be used to test the quality of the software. This can be attributed to the fact that quality means different things to different professionals. To some professionals quality means meeting of user requirements and ease of use by the user, where as to some other professionals it means that the software should be easily maintainable, portable and error free.

ERP system success measurement is the area which is still having not much work done. As a large amount is expected to be invested by SMB's in India and also all over the world in next few years in ERP, it is the high time that the quality of ERP should be investigated in operative phase. According to Kalyan Banga, Manager, Product Development, Netscribes India, Currently, the market is estimated at INR 400.2 Billion and is anticipated to achieve a CAGR of $25 \%$ to reach INR 983.4 Billion by 2015 [1]. According to Gartner principal research analyst Asheesh Raina, India will become the fourth largest enterprise software market in Asia Pacific this year and the country is forecast to account for 11 per cent of the region's total revenue of $\$ 29.33$ billion. By 2016, India's share of the software market in Asia Pacific is expected to reach 12.1 per cent, representing \$ 5.4 billion in revenue [2]. Also ERP is in the five, fastest-growing segments in India. And a study by AMI Partners reveals that of the 4.1 million Indian Small Mid Business with PC

Manuscript received February 4, 2013; revised May 8, 2013.

The authors are with National Institute of Technology Raipur, India (e-mail: Surajmukti@yahoo.com,priyanka_tripathi@hotmail.com). penetration almost a million would consider investing in an ERP solution in the next four years [3]. According to Naperville, the ERP Software market in India is expected to grow at a CAGR of 22.2 percent over the period 2011-2015 [4]. One of the key factors contributing to this market growth is the growing demand of ERP in SMBs [3], [4]. In the early 1990's most people and companies were unaware of ERP and its implications. However today close to $90 \%$ of the companies in the large enterprise segment (> 15000 million Indian Rupee) have embraced ERP. Similarly close to $60 \%$ companies in the Indian Rupee 3000 - 15000 million segments i.e. the mid-market have implemented ERP. Different reports are available giving percentage of failure of ERP. In a report by a contributor to CIO.com, data was revealed showing that enterprise resource planning projects have only a $7 \%$ chance of coming in on time, under budget, and providing satisfying results. Meaning the other 93\% are failures or challenged. ERP implementations have yielded more failures than successes [5].

As can be seen building an ERP is an expensive proposition. The consequences of failure would be disastrous. Inspite of great advancements in software development, ERP failure is fairly common. A 1997 KPMG survey said that over $61 \%$ of ERP projects had failed [6]. In 2001, Robbins-Gioia found that $51 \%$ of its survey participants claimed unsuccessful ERP implementations. Even today, claims of failure rates as high as $81 \%$ can be easily found [7]. Nevertheless, there are several lawsuits against ERP providers. The parties involved include vendors viz SAP, Lawson, Oracle, IBM, Epicor, etc., consultants such as Deloitte, universities (Ex: Montclair State University), governments (New York City, Marin county), and even nurses form Nova Scotia (Wailgum, 2009). ERP failures can cause a big mess, and result in significant losses. An example of this is Hershey. The company spent approximately $\$ 113$ million for ERP implementation. The entire project took 30 months. The time at which the ERP went live was Halloween, amongst the busiest times of the year. The software didn't function properly; there were delays in shipping and loss of customers. The company lost around \$151 million [8]. Nike the world-renowned shoe- and athletic gear-maker $\$ 100$ million in lost sales, a 20 percent stock dip and a collection of class-action lawsuits [9]. There are several challenges in ERP. Compounded to this entire most ERP vendors offer a "one shirt fits all concept" where typically the product they sell to the large vendors and the SMB's is more or less the same. Also the products are too generic and rarely take into consideration the unique requirements of the SMB's business. 


\section{LITERATURE SURVEY}

In the most general sense, software quality is conformance to explicitly state functional and performance requirements, explicitly documented development standards, and implicit characteristics that are expected of all professionally developed software. This definition serves to emphasize three important points: Software requirements are the foundation from which quality is measured. Lack of conformance to requirements is lack of quality; Specified standards define a set of development criteria that guide the manner in which software is engineered. If the criteria are not followed, lack of quality will almost surely result and, there is a set of implicit requirements that often goes unmentioned. If software conforms to its explicit requirements but fails to meet implicit requirements, software quality is suspected.

Many authors have discussed domain specific quality models because; a common generic model is difficult to define. However, international standardization bodies such as ISO and CEN (European) are trying to integrate different approaches to the definition of quality, starting from awareness that the quality as an attribute which changes developer's perspective. Regarding this ISO 13407, ISO9241-11, ISO 9126-1 standards and guidelines are there. The main purpose of software quality evaluation is to supply referential quantitative results to the software products that are reliable, understandable and acceptable to anyone's interest [10]. Quality is an intrinsic and multifaceted characteristic of a product [11]. Quality is not an absolute; it depends on the appraiser's perspective. Hence any quality measure must be subjective; summarizing the impression of a given class of individuals that interact with the product [12].Same is the case with the quality model applied to evaluate an ERP. ISO 9126 is a generalized model to evaluate a software package [13]. Similarly most widely used Information System (IS) success measurement model De Lone and McLean (1992, De Lone and McLean, 2002, De Lone and McLean, 2003) is also a generalized model for information system success [14]-[16].Some of the widely cited Information System success models used for ERP are the De Lone McLean (D\&M) I/S Success Model, Gable et al. model[17] etc. The most referred to model for success measurement in the field of IS is the De Lone and McLean (De Lone and McLean 1992, De Lone and McLean, 2002, De Lone and McLean, 2003) model which moved to a user centered approach when trying to judge overall IS success. The De Lone and McLean model consists of six interdependent measurements of success. System quality, information quality, use, user satisfaction, individual impact and organizational impact are the main measurement dimensions. Gabel et al. model has the four quadrants-(1) individual impact, (2) organizational impact, (3) information quality, and (4) system quality - representing four distinct but related dimensions of the multidimensional phenomenon: enterprise systems success. When evaluating an enterprise system, measures of these dimensions represent a snapshot of the organization's experience of the enterprise system at a point in time. The impact dimensions are an assessment of benefits that have followed (or not) from the system [18]-[20]. Evaluation of success is a difficult approach and it only makes sense if the result of an evaluation is used as a basis for actions which can result in an improvement of the systems performance (Stephan A. Kronbichler et.al. 2010) [21]. The quality dimensions reflect future potential. Together, these four dimensions reflect an ostensibly complete view of the enterprise system - an overarching measure of enterprise systems success. Ifinedo [22], [23] extended the dimensions of success proposed by Gable et al. because of the growing body of knowledge in this research field. The author found through literature review and interviews that ERP systems success measurement models might be limited because 2 important dimensions may not be considered.

One new dimension which was added to the model was the Vendor/Consultant Quality because the result of empirical evidence revealed that firms tend to associate the role and quality of the providers of their software with its overall success of the organization [24], [25]. ERP-projects are very complex and take a lot of time, that's why competent partners are needed. A know-how transfer and mixture between internal and external staff is necessary to manage it. Vendor / consultant quality measures the influence of external quality on the ERP-systems success. Vendor and consultant are grouped together because they represent an external source in the model. A very analytical approach described in Olsina (2001) proposed a Web-site Quality Evaluation Method grounded in a logic multi-attribute decision model and procedures, intended to be a useful tool to evaluate artifact quality in the operational phase of a Web Information System. Also the evaluation process has been done for the web-sites of Indian e-commerce domain.

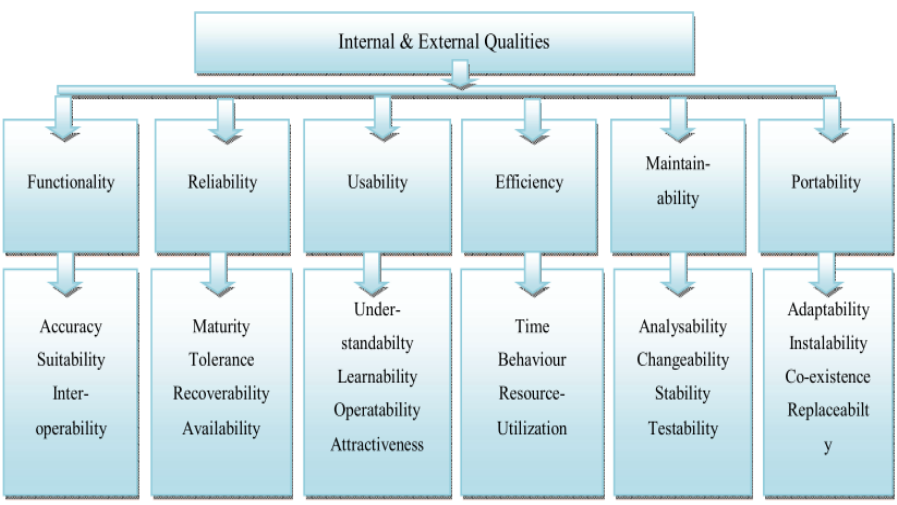

Fig. 1. ISO 9126 model for quality.

ISO 9126 is an international standard for the evaluation of software. The ISO/IEC 9126 defines three views of quality namely the user, manager, and developer. Users are interested in external quality characteristics, i.e., the quality in use. The developers and managers are interested in internal quality characteristics such as maintainability, portability etc. The standard is divided into four parts which addresses namely the quality model, external metrics, internal metrics and quality in use metrics. The ISO 9126-1 is an extension of previous work done by Boehm (1976), Covano and McCall (1978), and others in defining a set of software quality characteristics. The ISO 9126 quality model identifies following 6 main quality characteristics (Fig. 1) namely: Functionality, Reliability, Usability, Efficiency, Maintainability and Portability. Software measures and metrics are often indirectly measured and therefore open to debate. In the most general sense, software quality is, 
conformance to explicitly stated functional and performance requirements, explicitly documented development standards, and implicit characteristics that are expected of all professionally developed software. This definition serves to emphasize three important points: Software requirements are the foundation from which quality is measured. Lack of conformance to requirements is lack of quality; Specified standards define a set of development criteria that guide the manner in which software is engineered. If the criteria are not followed, lack of quality will almost surely result and, there is a set of implicit requirements that often goes unmentioned. If software conforms to its explicit requirements but fails to meet implicit requirements, software quality is suspect. These characteristics are further divided into sub-characteristics. Many authors have discussed domain specific quality models, because a common generic model is difficult to define. Software quality is monitored in two different ways:

1) The fixed model approach: We assume that all important quality factors needed to monitor a project are a subset of those in a published model. To control and measure each attribute, we accept the model's associated criteria and metrics and, most importantly, the proposed relationships among factors, criteria and metrics. Then, we use the data collected to determine the quality of the product. Boehm (1976) and Covano and McCall (1978) models are typical of fixed quality models.

2) The "Define your own quality model" approach: General philosophy of this approach states that quality is composed of' many attributes. To find out the quality characterization meeting with prospective users are arranged, to reach a consensus on which quality attributes are important for a particular product. Together, on a decomposition in which specific measures are decided for the lowest level attributes and specific relationships between them. Then, we measure the quality attributes objectively to see if they meet specified targets. 'Define your own Quality model' is given by Fenton and Pfleezer. The approach has been pioneered by Gilb T., (1969), Kitchenham and Walker, (2002). Gilb's method can be thought of as "design by measurable objectives"; it complements his philosophy of evolutionary development. The software engineer delivers the product incrementally to the user, based on the importance of the different kinds of functionality being provided to assign priorities to the functions; the user identifies key software attributes in the specification.

A quality model will be expressed in terms of factors and sub-factors or metrics which are directly measurable from the product. Thus, the quality of an ERP will be combined effect of these metrics and corresponding attached weights. For combining the effect of these metrics two scoring models are very commonly used. They are Linear Additive Scoring Model [Gibs] and Non-linear Multi scoring criteria. Suitable scoring model will be selected for evaluation.

\section{Designing ThE EVAluATION FrAmEWORK}

A general model of the evaluation framework is given in Fig. 2. It shows an initial phase which includes the identification of the evaluation requirements, a design phase in which the evaluation plan and techniques are defined, and a final ranking as per the quality and suggestion phase.

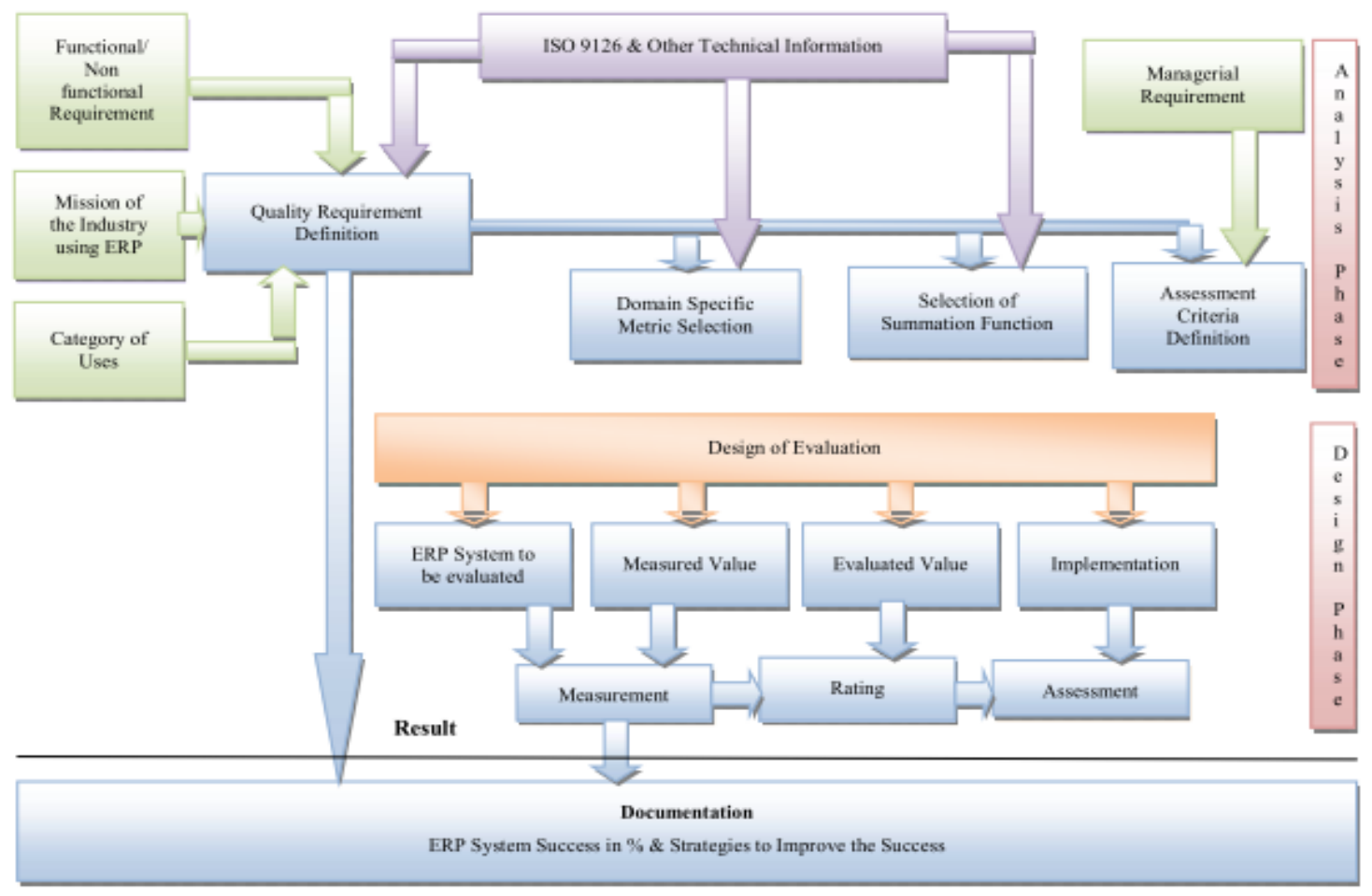

Fig. 2. Quality evaluation framework for ERP.

- Phase I: Quality requirements specification: What is the mission of the Industry? Specify the (a) functional Usability, Functionality and (b) non-functional quality requirements such as Reliability, Efficiency of the web-applications. What is the priority associated with each of the factors. Identify the category of users Outcome of this phase is evaluation goals. The reason for this is because the users always compare the ERP with the existing legacy system in other words ERP should have a greater usability. 
- Phase II. Metrics selection: Select the metrics, their corresponding weights the scale of measurement, and for summation. Outcome of this phase is evaluation plans.

- Phase III. Measurement: Measurement implementation and result calculation.

- Phase IV. Result: Ranking of ERP as per the Global Quality Preference. Suggestions for the evaluated ERP.

\section{CONCLUSION}

It is important to mention here that this is not an evaluation of a particular ERP product; rather it is the evaluation of entire system which comprises that ERP and the working environment and culture of that enterprise, i.e. ERP product in its operative phase. It is expected that organizations need to define their own quality factors, criteria and metrics specific to their system context. In future, we suggest creation of a knowledge base of ERP software's quality factors, criteria, and metrics. Software professionals can then make use of already defined model that suits them or find the closest model and modify it according to their needs. We further wish to evaluate selected Indian industries using ERP to calculate their Quality.

\section{REFERENCES}

[1]. J. U. Duncombe, "Infrared navigation-Part I: An assessment of feasibility," IEEE Trans. Electron Devices, vol. ED-11, pp. 34-39, Jan 1959.

[2]. C. Y. Lin, M. Wu, J. A. Bloom, I. J. Cox, and M. Miller, "Rotation, scale, and translation resilient public watermarking for images," IEEE Trans. Image Process, vol. 10, no. 5, pp. 767-782, 2001.

[3]. Reportstack. [Online]. Available: http://www.reportstack.com/product/79230/erp-software-market-in-in dia-2011-2015.html

[4]. ERP Software Market in India 2011-2015. [Online]. Available: http://www.researchandmarkets.com

[5]. B. Y. Chung, "An analysis of success and failure factors for ERP systems in engineering and construction firms," Ph.D. Dissertation, 2007.

[6]. R. Ghosh, "A comprehensive study on ERP failures stressing on reluctance to change as a cause of failure," Journal of Marketing and Management, vol. 3, no. 1, pp. 123-134, May 2012.

[7]. T. Wailgum. (2009). 10 famous ERP disasters, dustups and disappointments. [Online]. Available: http://www.cio.com/article/486284/10_Famous_ERP_Disasters_Dust ups_and_Disappointments

[8]. C. Koch. Nike Rebounds: How (and Why) Nike Recovered from Its Supply Chain Disaster. [Online]. Available: http://www.cio.com/article/32334/Nike_Rebounds_How_and_Why_ Nike_Recovered_from_Its_Supply_Chain_Disaster

[9]. R. C. Tausworthe, "Software quality management through process and product modeling," Annals of Software Engineering, vol. 1, no. 1, pp. 119-139, 1995

[10]. W. M. Gentleman, "Is software quality is a perception, how do we measure it?" in Proc. The 6th I.C. on Software Quality, Ottawa, October, 1996, pp. 32-43.

[11]. Software engineering - Product quality -Part 1: Quality model, ISO, 2001, ISO/IEC 9126-1,

[12]. K. S. Wei, A. C. Y. Loong, and Y. M. K. B. Ooi, "Measuring ERP system success: A respecification of the DeLone and McLean's is success model," Symposium on Progress in Information \& Communication Technology, pp. 7-8, 2009.

[13]. W. H. DeLone and E. R. McLean, "Information systems success: the quest for the dependent variable," Information systems research, vol. 3, no. 1 , pp. 60-95, 1992.

[14]. W. H. Delone and E. R. Mclean, "The DeLone and McLean model of Information systems success: A ten-year update," Journal of Management Information Systems, vol. 19, no. 4, pp. 9-30, 2003.
[15]. G. Gable, D. Sedera, and T. Chan, "Enterprise systems success: A measurement model," ICIS 2003 Proceedings, vol. 48, pp. 576-591, 2003.

[16]. N. E. Fenton and S. L. Pfleeger, Software Metrics a Rigorous and Practical Approach, Boston: PWS Publishing Company, 1997.

[17]. B. Boehm, J. Brown, and M. Lipow, "Quantitative evaluation of software quality," in Proc. the 2nd international conference on Software engineering, 1976, pp. 592-605.

[18]. J. Covano and J. McCall "A framework for the measurement of software quality." in Proc. ACM Software Quality Assurance Workshop, November, 1978, pp. 133-139.

[19]. T. Gilb, "Weighted ranking by levels," IAG Journal, vol. 2, no. 2, pp. 7-22, 1969.

[20]. B. A. Kitchenham, S. L. Pfleeger, L. M. Pickard, P. W. Jones, D. C. Hoaglin, K. El Emam, and J. Rosenberg, "Preliminary guidelines for empirical research in software engineering," IEEE Transactions on Software Engineering, vol. 28, no. 8, pp. 721-734, August 2002.

[21]. S. A. Kronbichler, H. Ostermann, and R. Staudinger, "A comparison of ERP-success measurement approaches," Journal of Information Systems and Technology Management, vol. 7, no. 2, pp. 281-310, 2010.

[22]. P. Ifinedo, "Investigating the relationships among ERP systems success dimensions: A structural equation model," Issues in Information Systems, vol. viii, no. 2, 2007.

[23]. P. Ifinedo and N. Nahar, "Quality, impact and success of ERP systems: A study involving some firms in the Nordic-Baltic region," Journal of Information Technology Impact, vol. 6, no. 1, pp. 19-46, 2006.

[24]. L. Olsina and G. Rossi, "Measuring web application quality with WebQEM," IEEE Multimedia, vol. 9, no. 4, pp. 20-29, 2002.

[25]. P. Tripathi and M. Kumar, "Ranking of indian E-Commerce web-applications by measuring quality factors," in Proc. 9th ACIS, IEEE International Conference on Software Engineering, Artificial Intelligence, Networking, and Parallel/Distributed Computing, 2008, pp. 949-954.

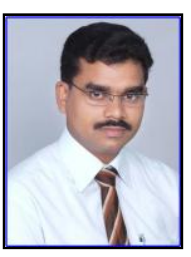

Suraj Kumar Mukti is appointed as an Assistant Professor in the department of Mechanical Engineering at National Institute of Technology Raipur Chhattisgarh. He has teaching experience of twelve years in the field of technical education. Suraj Kumar Mukti is the Lifetime Member of The Institute of Engineers (India) and teaching the AMIE students on honorary basis. Presently he is pursuing his Ph.D. program in the field of Management and Technology from National Institute of Technology Raipur Chhattisgarh.

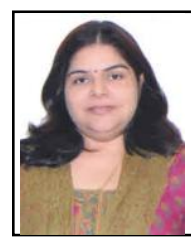

Priyanka Tripathi is appointed as an Assistant Professor in the department of Master of Computer Application at National Institute of Technology Raipur Chhattisgarh. She has completed her Ph.D. from MANIT Bhopal MP. She has also worked with Tata Consultancy Services TCS. She is the Lifetime Member of The Computer Society of India. She is dealing various typical subjects like ERP in the institute.

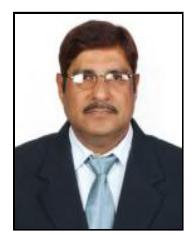

A. M. Rawani is a professor in Mechanical Engineering and Dean (Academic) at National Institute of Technology, Raipur. He has received his M.Tech. in Industrial Engineering and Management from IIT, Kharagpur and Ph.D. from I.I.T. Delhi. He has more than 30 years of teaching/research and administrative experience in Govt. Engg. Colleges /NIT.

$\mathrm{He}$ is the Editor-in-Chief of 'International Journal of Strategic Management and Business' and also of 'Journal of Information and Operations Management' (ISSN 0976-7762), Bioinfo Publications. He is Editor-in-Chief of 'International Journal of Trade, Economics and Finance', IACSIT Publication, Singapore (ISSN 2010-023X). $\mathrm{He}$ is also Editor-in-Chief of 'International Journal of Social Science and Humanity', IACSIT Publications Singapore. (ISSN 2010-3646). He is member of Editorial Board and reviewer of International Journal of Engineering, Science and Technology (IJEST), Nigeria (ISSN 2141-2839/2820). He is also Reviewer of African Journal of Business Management, South Africa. He has produced one Ph.D. and currently supervising four more candidates for their doctoral program. 